\title{
Familial Mediterranean Fever (FMF): Mysterious Presentations and Challenging Points From Diagnosis to Management in Acute Care Settings; A Literature Review
}

\author{
Soleyman Heydari ${ }^{1,2}$, Hosein Namdar ${ }^{3}$, Mohammad Javad Behzadnia ${ }^{2,4^{*}}$ \\ 'Department of Surgery, Baqiyatallah University of Medical Sciences, Tehran, Iran \\ ${ }^{2}$ Trauma Research Center, Baqiyatallah University of Medical Sciences, Tehran, Iran \\ ${ }^{3}$ Cardiovascular Research Center, Tabriz University of Medical Sciences, Tabriz, Iran \\ ${ }^{4}$ Department of Emergency Medicine, Baqiyatallah University of Medical Sciences, Tehran, Iran
}

Corresponding Author: Mohammad Javad Behzadnia, MD, Assistant Professor, Trauma Research Center, Baqiyatallah University of Medical Sciences, Molla Sadra St., Vanaq Sq., Tehran, Iran. Tel: +98-2181262012,

Email: Behzadnia@bmsu.ac.ir

Received July 14, 2019; Accepted November 17, 2019; Online Published December 15, 2019

\begin{abstract}
Introduction: Familial Mediterranean fever (FMF) is an autosomal recessive disease considered to be the most common entity of a rare group of disorders known as auto-inflammatory syndromes which have acute presentations in emergency settings.

Methods: A search of Web of Science, Google Scholar, Cochrane, and PubMed databases for articles published before January 2019 was performed using relevant keywords. Full-text English articles, including review articles, case series, and experimental studies, were evaluated. Unrelated studies were excluded. Based on the selected keywords, 440 studies were selected for review. Ultimately, 60 met the study criteria for final assessment.

Results: Given the various symptoms and the multiplicity of differential diagnoses, physicians may easily miss diagnosing FMF. Accordingly, emergency medical staff must be trained in order to significantly reduce the number of medical errors and economic costs and to improve the quality of life of involved patients.

Conclusion: Although FMF is already known to be an inflammatory entity, more study and investigation of it is required. There is an educational gap in both medical and general populations that should be filled by using new genetic testing and providing appropriate social and medical education.

Keywords: Familial Mediterranean Fever, Emergency Medicine, Surgery, Acute Abdomen
\end{abstract}

Citation: Heydari S, Namdar H, Behzadnia MJ. Familial Mediterranean fever (FMF): Mysterious presentations and challenging points from diagnosis to management in acute care settings; a literature review. Int J Travel Med Glob Health. 2019;7(4):118-122. doi:10.15171/ijtmgh.2019.25.

\section{Introduction}

Familial Mediterranean fever (FMF) is an autosomal recessive inherited disease most commonly seen in the first two decades of life. ${ }^{1-4}$ Afflicted patients present with intermittent periodic fever (commonly lasting not more than 3 days), generalized abdominal pain, peritonitis, chest pain, pleuritis, skin rashes, or even arthritis; concurrent arthritis is more prevalent in the ankle, knee, and hip joints. ${ }^{1,3,5-8}$

FMF affects more than 150000 patients worldwide. It is seen mostly in males with the first episode occurring before the age of 20 years. Its appearance in patients above the age of 50 is extremely rare. In a study by Majeed et al, most patients were diagnosed before the age of 5 years. ${ }^{9-11}$ This disorder is usually diagnosed by physical examination, symptoms and signs; however, today, it is more easily recognized through molecular and genetic advances. In the case of a positive familiar history, the presence of inflammatory episodes of fever could be suggestive. ${ }^{12}$

As indicated by its name, FMF is known to occur mainly among Mediterranean and Middle Eastern populations, such as non-Ashkenazi Jews, Arabs, Turks, and Armenians. During recent years, however, more cases have been reported from other countries like Italy, Japan, and Australia. ${ }^{13-21}$

FMF may mimic conditions seen in acute appendicitis, cholecystitis, some infections, and arthritis. This may lead to various evaluations and may even delay the correct diagnosis for many years. ${ }^{22}$

Despite the fever, usually no pathogen is found. FMF may

Copyright $\odot 2019$ The Author(s). This is an open-access article distributed under the terms of the Creative Commons Attribution License (http:// creativecommons.org/licenses/by/4.0), which permits unrestricted use, distribution, and reproduction in any medium, provided the original work is properly cited. 
present as severe intermittent abdominal pain and fever. Thus, patients referring to the emergency department may be diagnosed with acute abdomen and even undergo unnecessary surgery. In the case of atypical symptoms, decision-making is more difficult and may result in incorrect therapy or delayed appropriate treatment. Molecular and genetic assessments are useful in achieving the best results in atypical cases.

FMF may also accompany other systemic diseases like vasculitis, multiple sclerosis (MS), inflammatory bowel disease, and spondyloarthropathies. ${ }^{23}$

Because of the gap in diagnosis and treatment in more involved countries, the current study was designed based on the following research questions: What are the emergency presentations of FMF? How should the physician determine and manage them in emergencies? This study reviews and emphasizes the importance of precise physical examination and previous clinical history in making a better diagnosis and avoiding unnecessary surgeries and interventions in emergency settings.

\section{Methods}

\section{Search Strategy}

To find previously published studies relevant to the current study question, a search of the Web of Science, Google Scholar, Cochrane, and PubMed databases was performed for articles published before January 2019 using the keywords "Familial Mediterranean Fever", "Emergency Medicine", "emergency", "surgery", "abdominal pain", and "acute abdomen". A combination search based on Mesh terms was also performed. The PRISMA checklist was used to evaluate the validity of the selected articles. ${ }^{24}$

In various steps, the title, summary, methodology, results, and discussion of the selected studies were assessed. Initially, the titles and abstracts were assessed and saved to EndNote X8. Then, the full-text of English review articles, case series, and experimental studies were evaluated. Letters and duplicate studies were excluded. In the next stage, full texts were reviewed by two independent experts, and unrelated studies were excluded. Some similar and duplicate studies had no new information. Some other papers for which the full text was not available were excluded in the second and third stages. Among 440 studies initially reviewed, 60 met the study criteria for final assessment. Based on the different presentations reported in various selected papers, the methods of diagnosis and medical management were arranged to present the challenging points of FMF in acute settings (Figure 1).

\section{Results}

FMF is the most common of a rare group of disorders collectively termed familial hereditary periodic fever syndromes, also known as auto-inflammatory syndromes. It was clinically described over 60 years ago. ${ }^{19,25}$

It has 3 phenotypes. Type 1 is presented by brief episodes of serositis and inflammation such as synovitis, pleuritis, and pericarditis with different levels of severity. Type 2 is characterized by amyloidosis as the predominant presentation, and type 3 is referred to as the silent phenotype..$^{26,27}$

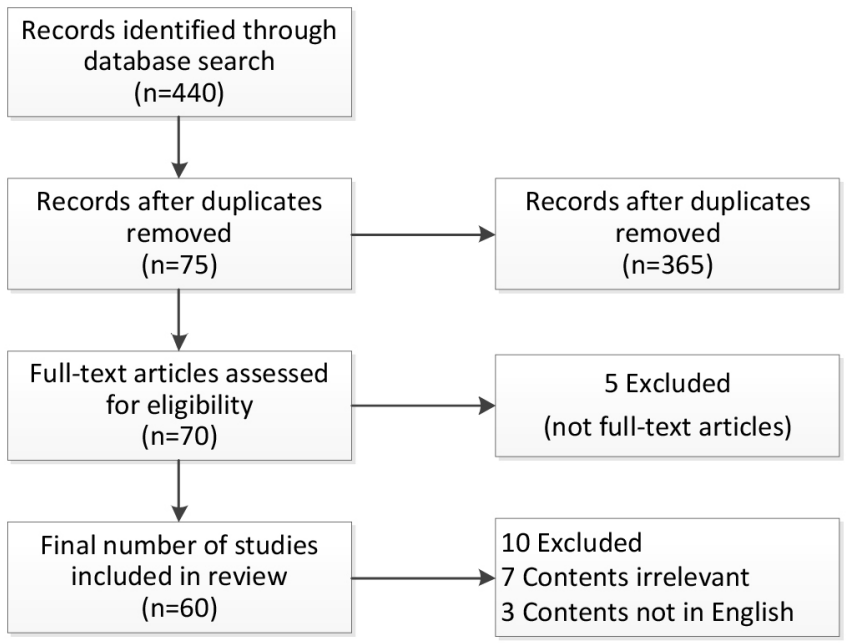

Figure 1. Flow Chart for Article Selection.

FMF is clinically characterized by intermittent bouts of fever with peritonitis and abdominal pain, pleuritis, arthritis, or erysipelas-like rashes, so several disorders may be standing on a differential diagnosis. ${ }^{28}$

In non-emergency conditions, FMF may also present as chronic abdominal pain, and the patient may take many paraclinical tests before the diagnosis is made. ${ }^{29}$ Many patients may undergo excessive evaluations, wasteful surgeries, and even psychological assessments. In a study in Australia, 50\% of the children with a final diagnosis of FMF underwent unnecessary operations for acute abdomen. ${ }^{30,31}$

Clinical evaluation is the cornerstone of diagnosis. Welltimed treatment may improve a patient's prognosis and result in diminished complications. ${ }^{32}$ Untreated patients, on the other hand, may experience serious complications such as progressive renal disease, infertility, growth retardation in children, and secondary amyloidosis due to amyloid deposition in organs such as the digestive tract or kidneys. ${ }^{22}$

Fever and abdominal pain are the main clinical presentations of FMF. Abdominal pain is the most prevalent grievance (74\%$95 \%)$. Its flares simulate acute abdomen or an abdominal rigidity that resolves spontaneously, but accurate diagnosis and correct subsequent treatment are necessary to distinguish life-threatening bowel obstruction and strangulation. .,33 $^{1,3}$

Infrequent gastrointestinal signs and symptoms such as non-specific abdominal pain, ileus, diarrhea, ascites, and even eosinophilic esophagitis are also reported, ${ }^{29,34}$ with which diagnoses could easily be missed.

Secondary amyloidosis is the most severe complication of FMF. It is associated with continuous inflammation and secondary amyloid deposition in the gut, spleen, liver, heart, and other organs..$^{32,35}$

Females may experience problems, especially in puberty, fertility, and pregnancy. Patients may also complain of recurrent gross hematuria as another rare presentation. ${ }^{36,37}$

Inflammatory bouts are characterized by short-term and self-limited abdominal, thoracic, and/or articular symptoms which wane spontaneously. ${ }^{38}$ In many conditions, a high level of cytokines and acute-phase proteins indicate an 
inflammation response. ${ }^{39,40}$ Accordingly, FMF is associated with SLE as an inflammatory disease. ${ }^{41}$

Central nervous system involvement, such as MS and cerebrovascular accident, are reported as extremely rare presentations of FMF by some studies. ${ }^{42,43}$

Pericarditis is another complication that may be related to FMF. It has a good response to colchicine. Acute lung attacks in FMF may occur in an acute setting, but it is mostly limited to transient pleuritis. ${ }^{44,45}$

Laboratory findings are usually nonspecific. A moderate leukocytosis may be seen during flares. There are no specific or standard laboratory tests for FMF, but high levels of erythrocyte sedimentation rate, fibrinogen, CRP, beta2 and alpha2 $\mathrm{M}$ globulins, haptoglobin and lipoprotein concentrations, leukocytosis, and diminished albumin concentration could be detected..$^{33,46}$

Mutations in the MEFV gene encoding pyrine, a natural precursor of pro-inflammatory molecules, result in uncontrolled relapsing systemic inflammation, increased leukocyte migration to serosal membranes or joints, and inappropriate response to inflammatory stimuli. These findings are useful for better diagnosis and treatment., ${ }^{4,437-50}$ Furthermore, FMF has recently been associated with the angiotensin-converting enzyme gene in Turkish patients. ${ }^{42}$

Today, physicians still need to know more about FMF. In a study in Iran, more than 50\% of the parents of FMF patients were first-degree relatives. Of the patients, $60 \%$ had delayed diagnoses, while $30 \%$ underwent unnecessary surgery; hence, a more focused detailed assessment is necessary to achieve a correct diagnosis. ${ }^{51}$

Few studies in Iran have explained this regional disease, especially in the northwest of the country which has a high Turkish population. Some cases have been reported from different parts of the country as the population of Turkish origin has a scattered distribution in Iran. To the best of the authors' knowledge, the majority of FMF cases in Iran have occurred in people who have Turkish origins.

\section{Discussion}

The frequency of FMF attacks differs significantly among various races and in individual patients. Because the symptoms may last days or years, the physician may easily miss the diagnosis. As mentioned, FMF is a hereditary inflammatory disease with an autosomal recessive transmission due to mutations in the MEFV gene. The MEFV gene, located on the short arm of chromosome 16, codes an anti-inflammatory protein or pyrine. ${ }^{47}$ A mutation on chromosome 16 leads to pyrine mal-synthesis gene and innate immune system activation. ${ }^{13,16,49,52-54}$

Recent studies have shown that the Iranian genotype is similar to that of Arabs and Armenians, although its presentation is more similar to the Turkish and Iraqi populations. ${ }^{55,56}$ No significant relationship between some gene mutations and amyloidosis has been shown in recent Iranian studies. ${ }^{57}$ In a cross -sectional study, 10 mutations in the FMF gene (MEFV) were recognized in an affected FMF population in northwestern Iran. $^{57}$

More than $50 \%$ of documented Iranian patients were not diagnosed by MEFV gene mutations; to date, the TelHashomer clinical criteria have been the proper method of diagnosis in Iran. $^{56}$

As mentioned, FMF is a disease of early-onset, and delays in diagnosis and treatment may lead to more complications and prolonged morbidities. In many cases, the inflammatory process may present even in the absence of any symptoms. ${ }^{40,58}$

FMF is recognized as an inflammatory endemic disease characterized by self-limited events of polyserositis. Thus, periodic attacks of FMF respond to drugs such as colchicine which decreases the attack frequency and prevents the occurrence of amyloidosis. ${ }^{50,59}$ A positive response to treatment with colchicine is mentioned in more than $95 \%$ of patients with two mutated alleles. ${ }^{60}$ The effectiveness of colchicine as the drug of choice has been approved by some studies, but biological drugs seem to be an alternative for non-responsive patients. Based on undocumented data, some patients suspected of having FMF were successfully treated with colchicine. One study reported that regular colchicine treatment even led to a significant improvement in femoral bone mineral density. ${ }^{61}$

\section{Conclusion and Recommendation for Future Research}

Genetic testing can help distinguish numerous causes among various populations. A few unconfirmed patients have even been treated blindly with colchicine. Unfortunately, the high cost of genetic testing is the main reason most patients in developing countries are not diagnosed with this method.

Ultimately, clinical assessment is the cornerstone of diagnosis. As FMF significantly influences patient quality of life, it is very important to correctly diagnose and control this disease. ${ }^{15,53}$

Although FMF is already known as an inflammatory disease, more study and investigation of this disease is still needed. There is an education gap in both medical and general populations that should be filled using social media and newspapers accompanied by medical education.

The creation of specific virtual educational centers and education programs for affected patients in more involved countries could help to identify most affected patients and reduce the social costs associated with FMF.

Having a positive family history may increase a person's risk for FMF. People should be aware of the symptoms and when to see a doctor. While there is no cure for this disease, proper diagnosis and treatment could relieve its signs and symptoms and even prevent the exacerbation of this disorder. Hence, it could also help to improve the patient's quality of life. Emergency physicians should especially be aware of the various presentations of FMF and play the main role in its diagnosis and treatment. Early correct diagnosis and treatment in accordance with the patient's environment and genetic history may prevent unnecessary workups and subsequent future complications.

\section{Limitation}

Only available full-text English language articles were reviewed in this study; thus, a few relevant studies may have been missed. 
Review Highlights

\section{What Is Already Known?}

Familial Mediterranean Fever is a well-known disorder; nevertheless, many young physicians are not familiar with its various presentations or its management, even in involved countries, thus risking delays in diagnosis and even unnecessary costs.

\section{What This Study Adds?}

This study highlights the important educational gap and focus on the different presentations of FMF in acute settings to match the previous learnings with new educational concepts.

\section{Authors' Contributions}

All the authors contributed equally to this study.

\section{Conflict of Interest Disclosures}

The authors declare that they have no conflicts of interest associated with this study.

\section{Ethical Approval \\ Not applicable.}

\section{Funding/Support}

None.

\section{References}

1. Yonem O, Bayraktar Y. Secondary amyloidosis due to FMF. Hepatogastroenterology. 2007;54(76):1061-1065.

2. Fonnesu C, Cerquaglia $C$, Giovinale $M$, et al. Familial Mediterranean Fever: a review for clinical management. Joint Bone Spine. 2009;76(3):227-233. doi:10.1016/j.jbspin.2008.08.004.

3. Ureten K, Bostanci A, Akbal E, Gönülalan G, Ozbek M, Oztürk MA. Familial Mediterranean fever with chronic ascites: a case report and a review of literature. Rheumatol Int. 2009;29(12):1477-1480. doi:10.1007/s00296-009-0842-6.

4. Meinzer U, Quartier P, Alexandra JF, Hentgen V, Retornaz F, KonéPaut I. Interleukin-1 targeting drugs in familial Mediterranean fever: a case series and a review of the literature. Semin Arthritis Rheum. 2011;41(2):265-271.doi:10.1016/j.semarthrit.2010.11.003.

5. Gok F, Sari E, Erdogan O, Altun D, Babacan O. Familial Mediterranean fever and IgA nephropathy: case report and review of the literature. Clin Nephrol. 2008;70(1):62-64. doi:10.5414/ cnp70062.

6. Dbouk HA, Uthman IW. An overview of familial Mediterranean fever with emphasis on pyrin and colchicine. J Med Liban. 2008;56(1):35-41.

7. Leclercq P, Hermesse A, Malaise MG. [Familial Mediterranean fever]. Rev Med Liege. 2004;59(5):320-325.

8. Ozen S. New interest in an old disease: familial Mediterranean fever. Clin Exp Rheumatol. 1999;17(6):745-749.

9. Yanmaz MN, Özcan AJ, Savan K. The impact of familial Mediterranean fever on reproductive system. Clin Rheumatol. 2014;33(10):1385-1388. doi:10.1007/s10067-014-2709-9.

10. Vinceneux P, Pouchot J. [Familial Mediterranean fever, clinical and laboratory findings]. Presse Med. 2005;34(13):938-946. doi:10.1016/s0755-4982(05)84085-0.

11. Majeed HA, Barakat M. Familial Mediterranean fever (recurrent hereditary polyserositis) in children: analysis of 88 cases. Eur J Pediatr. 1989;148(7):636-641. doi:10.1007/bf00441519.

12. Estébanez Muñoz M, Gómez Cerezo J, Barbado Hernández FJ.
[The spectrum of familial Mediterranean fever]. Rev Clin Esp. 2007;207(10):508-509. doi:10.1157/13111550.

13. Rigante D, La Torraca I, Avallone L, Pugliese AL, Gaspari S, Stabile A. The pharmacologic basis of treatment with colchicine in children with familial Mediterranean fever. Eur Rev Med Pharmacol Sci. 2006;10(4):173-178.

14. Orbach H, Ben-Chetrit E. Familial Mediterranean fever - a review and update. Minerva Med. 2001;92(6):421-430.

15. Dallos T, Ilenčíková D, Kovács L. [Familial Mediterranean fever - clinical picture, diagnosis and treatment]. Vnitr Lek. 2014;60(1):30-37.

16. Simon A, van der Meer JW, Drenth JP. Familial Mediterranean fever--a not so unusual cause of abdominal pain. Best Pract Res Clin Gastroenterol. 2005;19(2):199-213. doi:10.1016/j. bpg.2004.11.009.

17. Migita K, Agematsu K. [Clinical aspects of Familial Mediterranean fever]. Nihon Rinsho Meneki Gakkai Kaishi. 2011;34(5):355-360. doi:10.2177/jsci.34.355.

18. El-Shanti H, Majeed HA, El-Khateeb M. Familial Mediterranean fever in Arabs. Lancet. 2006;367(9515):1016-1024. doi:10.1016/ s0140-6736(06)68430-4.

19. Nucera G, La Regina M, Diaco M, Neri G, Gasbarrini G, Manna R. [Familial Mediterranean fever: an ancient hereditary disease]. Ann Ital Med Int. 2003;18(3):136-148.

20. Takenaka K, Yanase T, Nagatomo H, Tanaka A, Nawata H. [A case of familial Mediterranean fever with obvious family history]. Nihon Naibunpi Gakkai Zasshi. 1994;70(10):1075-1082. doi:10.1507/ endocrine1927.70.10_1075.

21. Frenkel J, Bemelman FJ, Potter van Loon BJ, Simon A. [Familial Mediterranean fever: not to be missed]. Ned Tijdschr Geneeskd. 2013;157(18):A5784.

22. Zadeh N, Getzug T, Grody WW. Diagnosis and management of familial Mediterranean fever: integrating medical genetics in a dedicated interdisciplinary clinic. Genet Med. 2011;13(3):263269. doi:10.1097/GIM.0b013e31820e27b1.

23. Aksu K, Keser G. Coexistence of vasculitides with familial Mediterranean fever. Rheumatol Int. 2011;31(10):1263-1274. doi:10.1007/s00296-011-1840-z.

24. Preferred reporting items for systematic review and meta-analysis protocols (PRISMA-P) 2015: elaboration and explanation. BMJ. 2016;354:i4086. doi:10.1136/bmj.i4086.

25. Schaner PE, Gumucio DL. Familial Mediterranean fever in the post-genomic era: how an ancient disease is providing new insights into inflammatory pathways. Curr Drug Targets Inflamm Allergy. 2005;4(1):67-76. doi:10.2174/1568010053622803.

26. Soriano A, Manna R. Familial Mediterranean fever: new phenotypes. Autoimmun Rev. 2012;12(1):31-37. doi:10.1016/j. autrev.2012.07.019.

27. Shohat M, Halpern GJ. Familial Mediterranean fever--a review. Genet Med. 2011;13(6):487-498. doi:10.1097/ GIM.0b013e3182060456.

28. Bhat A, Naguwa SM, Gershwin ME. Genetics and new treatment modalities for familial Mediterranean fever. Ann N Y Acad Sci. 2007;1110:201-208. doi:10.1196/annals.1423.022.

29. Mor A, Gal R, Livneh A. Abdominal and digestive system associations of familial Mediterranean fever. Am J Gastroenterol. 2003;98(12):2594-2604. doi:10.1111/j.1572-0241.2003.08784.x.

30. Moore PJ, Mansour A, McDonald JD, Kemp A, Kamath KR, Dorney SF. Familial Mediterranean fever in six Australian children. Med J Aust. 1989;151(2):108-110. doi:10.5694/j.1326-5377.1989. tb101171.x.

31. Samuels J, Aksentijevich I, Torosyan Y, et al. Familial Mediterranean fever at the millennium. Clinical spectrum, ancient mutations, and a survey of 100 American referrals to the National Institutes of Health. Medicine (Baltimore). 1998;77(4):268-297. doi:10.1097/00005792-199807000-00005.

32. Ozturk MA, Kanbay M, Kasapoglu B, et al. Therapeutic approach to familial Mediterranean fever: a review update. Clin Exp 
Rheumatol. 2011;29(4 Suppl 67):S77-86.

33. Vinceneux P, Pouchot J. [Familial Mediterranean fever among the autoimmune diseases]. Presse Med. 2005;34(13):947-957. doi:10.1016/s0755-4982(05)84086-2.

34. Rohani P, Najafi Sani M, Ahmadi M, Ziaee V. A Case of Eosinophilic Esophagitis Accompanying Familial Mediterranean Fever. Case Rep Gastrointest Med. 2017;2017:6863921. doi:10.1155/2017/6863921.

35. Akpolat T, Özkaya O, Özen S. Homozygous M694V as a risk factor for amyloidosis in Turkish FMF patients. Gene. 2012;492(1):285289. doi:10.1016/j.gene.2011.10.012.

36. Nickavar A. Recurrent Macroscopic Hematuria and Abdominal Pain: Questions and Answers. Iran J Public Health. 2015;44(8):11431145.

37. Dotters-Katz S, Kuller J, Price T. The impact of familial Mediterranean fever on women's health. Obstet Gynecol Surv. 2012;67(6):357-364. doi:10.1097/OGX.0b013e318259ed3a.

38. Rigante D, Lopalco G, Tarantino G, Compagnone A, Fastiggi M, Cantarini L. Non-canonical manifestations of familial Mediterranean fever: a changing paradigm. Clin Rheumatol. 2015;34(9):1503-1511. doi:10.1007/s10067-015-2916-z.

39. Ozen S, Demirkaya E, Duzova A, et al. FMF50: a score for assessing outcome in familial Mediterranean fever. Ann Rheum Dis. 2014;73(5):897-901. doi:10.1136/annrheumdis-2013-204719.

40. Ben-Zvi I, Livneh A. Chronic inflammation in FMF: markers, risk factors, outcomes and therapy. Nat Rev Rheumatol. 2011;7(2):105112. doi:10.1038/nrrheum.2010.181.

41. Yildiz G, Kayatas M, Uygun Y, Timucin M, Candan F. Coexistence of systemic lupus erythematosus and familial Mediterranean fever. Intern Med. 2010;49(8):767-769. doi:10.2169/ internalmedicine.49.3102.

42. Nursal AF, Turkmen E, Uzun Kaya S, et al. Angiotensin converting enzyme gene insertion/deletion variant and familial Mediterranean fever-related amyloidosis. Iran J Kidney Dis. 2018;12(3):150-155.

43. Aghdashi M, Seidmardani SM, Vossoughian S, Seyed Mokhtari SA. Very Rare Presentation of Cerebrovascular Accident in 20-Year-Old Man With Familial Mediterranean Fever-Case Report. Clin Med Insights Case Rep. 2018;11:1179547617749208. doi:10.1177/1179547617749208.

44. Lidar M, Pras M, Langevitz P, Livneh A. Thoracic and lung involvement in familial Mediterranean fever (FMF). Clin Chest Med. 2002;23(2):505-511. doi:10.1016/s0272-5231(01)00002-8.

45. Halabe-Cherem J, Hamui-Sutton A, Cohen-Cohen S, et al. [Recurrent pericardial effusion due to familiar Mediterranean fever]. Rev Med Inst Mex Seguro Soc. 2009;47(2):211-214.

46. Medlej-Hashim M, Loiselet J, Lefranc G, Mégarbané A. [Familial Mediterranean Fever (FMF): from diagnosis to treatment]. Sante. 2004; 14(4):261-266

47. Ozen S, Demirkaya E, Erer B, et al. EULAR recommendations for the management of familial Mediterranean fever. Ann Rheum Dis.
2016;75(4):644-651. doi:10.1136/annrheumdis-2015-208690.

48. Wu B, Xu T, Li Y, Yin X. Interventions for reducing inflammation in familial Mediterranean fever. Cochrane Database Syst Rev. 2015(3):CD010893. doi:10.1002/14651858.CD010893.pub2.

49. Sozeri B, Kasapcopur O. Biological agents in familial Mediterranean fever focusing on colchicine resistance and amyloidosis. Curr Med Chem. 2015;22(16):1986-1991. doi:10.2174/092986732266615 0311152300 .

50. El-Shanti HE. Familial Mediterranean Fever. Saudi Med J. 2001;22(2):104-109.

51. Salehzadeh F, Emami D, Zolfegari AA, et al. Familial Mediterranean fever in northwest of Iran (Ardabil): the first global report from Iran. Turk J Pediatr. 2008;50(1):40-44.

52. Ozen S, Bilginer Y. A clinical guide to autoinflammatory diseases: familial Mediterranean fever and next-of-kin. Nat Rev Rheumatol. 2014;10(3):135-147. doi:10.1038/nrrheum.2013.174.

53. Shamov IA. [Familial Mediterranean fever (paroxismal polyserositis, familial recurring polyserositis, periodic disease)]. Klin Med (Mosk). 2014;92(3):31-34.

54. Ozen S. Familial Mediterranean fever: revisiting an ancient disease. Eur J Pediatr. 2003;162(7-8):449-454. doi:10.1007/ s00431-003-1223-x.

55. Beheshtian M, Izadi N, Kriegshauser G, et al. Prevalence of common MEFV mutations and carrier frequencies in a large cohort of Iranian populations. J Genet. 2016;95(3):667-674. doi:10.1007/ s12041-016-0682-6.

56. Salehzadeh F, Jafari AsI M, Hosseini Asl S, Jahangiri S, Habibzadeh S. MEFV gene profile in Northwest of Iran, twelve common MEFV gene mutations analysis in 216 patients with Familial Mediterranean Fever. Iran J Med Sci. 2015;40(1):68-72.

57. Jabbarpour Bonyadi M, Gerami SM, Somi MH, Dastgiri S. MEFV mutations in Northwest of Iran: a cross sectional study. Iran J Basic Med Sci. 2015;18(1):53-57. doi:10.22038/ijbms.2015.3889.

58. Giancane G, Ter Haar NM, Wulffraat N, et al. Evidence-based recommendations for genetic diagnosis of familial Mediterranean fever. Ann Rheum Dis. 2015;74(4):635-641. doi:10.1136/ annrheumdis-2014-206844.

59. Haddad JJ. The role of inflammatory cytokines and NFkappaB/MAPK signaling pathways in the evolution of familial Mediterranean fever: current clinical perspectives and potential therapeutic approaches. Cell Immunol. 2009;260(1):6-13. doi:10.1016/j.cellimm.2009.08.003.

60. Jabbarpour Bonyadi $M$, Somi $M H$, Pourmousavi Khoshknab MM, Eslami F, Montazam M, Gerami SM. FMF Genotypephenotype correlation in Iranian Azeri Turks: Association between M694V/R761H mutation and amyloidosis. Iran J Basic Med Sci. 2015;18(7):659-663.

61. Salah S, El-Masry SA, Sheba HF, El-Banna RA, Saad W. Bone mineral density in Egyptian children with familial Mediterranean fever. Iran J Med Sci. 2016;41(1):2-8. 